Working Paper 97-92

Business Economics Series 20

December 1997
Departamento de Economía de la Empresa

Universidad Carlos III de Madrid

Calle Madrid, 126

28903 Getafe (Spain)

Fax (341) 624-9608

\title{
INTEGRATION AND ARBITRAGE IN THE SPANISH FINANCIAL MARKETS: AN EMPIRICAL APPROACH
}

\author{
Alejandro Balbás*, Iñaki R. Longarela* and Ángel Pardo**
}

Abstract

Several authors have introduced different ways to measure the integration between financial markets. Most of them are derived from the basic assumptions to price assets, like the Law of One Price or the absence of arbitrage opportunities. Two perfectly integrated markets must give identical price to identical final payoffs, and a vector of positive discount factors, common to both markets, must exist. Therefore, if these properties do not hold, their degree of violation can be measured and considered as an integration measure.

The present paper empirically test the integration measures in the Spanish financial markets. Hence, several interesting values are obtained, like for instance, the state prices or the risk-neutral probabilities. Furthermore, when the risk-neutral probabilities do not exist, explicit cross-market arbitrage portfolios are detected.

The results of our test are surprising for several reasons. First of all, the arbitrage opportunities very often appear, and the bid-ask spread and the transaction costs are not able to avoid the arbitrage profits. Furthermore, the criticisms, which are usually argued when empirical papers show the existence of arbitrage opportunities, do not apply here, since we work with perfectly synchronized high frequency data. On the other hand, different integration measures show a similar evolution along the tested period, although these measures give different information about the markets efficiency and integration, and they do not have to be necessarily related.

\section{Key Words}

Integration, arbitrage profits, state prices, risk-neutral probability measure, efficient market.

"Universidad Carlos III de Madrid, Departamento de Economía de la Empresa, C/ Madrid, 126, 28903 Getafe (Madrid). Email: balbas@emp.uc3m.es

“Universidad de Valencia, Departamento de Economía Financiera y Matemáticas, Avda. Tarongers, s/n, 46071 Valencia Research founded by DGYCIT (Reference Number: PB95-0729-C02-02) and Fundación Caja de Madrid. 


\title{
INTEGRATION AND ARBITRAGE IN THE SPANISH FINANCIAL MARKETS: AN EMPIRICAL APPROACH. $\left({ }^{*}\right)$
}

by

\author{
Alejandro Balbás ${ }^{(1)}$, Iñaki R. Longarela ${ }^{(1)}$, and Ángel Pardo ${ }^{(2)}$ \\ (1) Universidad Carlos III. Dpto. de Economía de la Empresa. C/ Madrid 126, 28903 Getafe (Madrid, Spain). \\ ${ }^{(2)}$ Universidad de Valencia. Dpto. de Economía Financiera y Matemática. Avda. Tarongers s/n, 46071 \\ Valencia (Spain).
}

Abstract. Several authors have introduced different ways to measure the integration between financial markets. Most of them are derived from the basic assumptions to price assets, like the Law of One Price or the absence of arbitrage opportunities. Two perfectly integrated markets must give identical price to identical final payoffs, and a vector of positive discount factors, common to both markets, must exist. Therefore, if these properties do not hold, their degree of violation can be measured and considered as an integration measure.

The present paper empirically tests the integration measures in the Spanish financial markets. Hence, several interesting values are obtained, like for instance, the state prices or the risk-neutral probabilities. Furthermore, when the risk-neutral probabilities do not exist, explicit cross-market arbitrage portfolios are detected.

The results of our test are surprising for several reasons. First of all, the arbitrage opportunities very often appear, and the bid-ask spread and the transaction costs are not able to avoid the arbitrage profits. Furthermore, the criticisms, which are usually argued when empirical papers show the existence of arbitrage opportunities, do not apply here, since we work with perfectly synchronized high frequency data. On the other hand, different integration measures show a similar evolution along the tested period, although these measures give different information about the markets efficiency and integration, and they do not have to be necessarily related.

Key words and phrases. Integration, arbitrage profits, state prices, risk-neutral probability measure, efficient market.

\footnotetext{
* Research founded by DGYCIT (Reference Number : PB95-0729-C02-02) and Fundación Caja de Madrid.
} 


\section{Introduction}

The absence of arbitrage opportunities is a basic assumption, common to all the asset pricing models, usually characterized by the existence of positive state prices (Ingersoll (1987)) or, under the appropriate hypotheses, by the martingale property in dynamic approaches (see Harrison and Kreps (1979), Back and Pliska (1991) or Hansen and Richard (1987)).

Applying different procedures, and looking for different objectives, the absence of arbitrage has been very often tested in previous literature. Sometimes, the authors are interested in the financial markets degree of efficiency, and the integration among two or more markets is, in other situations, the main purpose of the analysis (see e.g. Chen and Knez (1995) or Kempf and Korn (1996)).

When empirical papers analyze the financial market efficiency, they usually focus on some well known trading rules or arbitrage portfolios. So for instance, Hudson et al (1996) test the simple technical trading rules, and Sternberg (1994) or Kamara and Miller (1995) test the existence of violations for the put-call parity . On the other hand, empirical analysis of financial markets integration are also implemented by testing the price of specific assets or portfolios in different markets (see for instance Harris et al (1995)) or, once again, by testing concrete arbitrage portfolios (Lee and Nayar (1993)), which are specially related to the Law of One Price when spot and future markets are simultaneously involved (Protopapadakis and Stoll (1993) or Kempf and Korn (1996)).

Focusing now on markets integration, a new look may be found in Chen and Knez (1995). To be precise, these authors consider the state prices to introduce a new integration measure, which is never smaller than zero, and must vanish in order to guarantee the absence of cross-market arbitrage opportunities. Therefore, testing their measure one globally tests the absence of (cross-market) arbitrage, and not only some specific or concrete strategies. The advantages of this new methodology are clear. First, although we could ensure that different markets were giving the same price to some specific securities, portfolios, or well known replicas, this is far of being a sufficient condition to guarantee the absence of cross-market arbitrage. Second, computing how often the Chen and Knez measure is greater than zero, we are analyzing how often the existence of a risk-neutral probability measure does not work out in practice.

The Chen and Knez measure is a very important contribution, but presents some difficulties pointed out by several authors. So for instance, once we have computed a positive value for the measure, this value does not provide information about the feasible arbitrage portfolios and their associate arbitrage profits, and Kempf and Korn (1996) consider that it is very difficult to judge the significance of any difference found between two estimated values of the measure. Balbás and Muñoz (1996) show that the measure is non continuous and very sensitive respect the initial data and parameters (prices for instance), and measurement errors could lead to serious mistakes. 
To avoid these difficulties, Balbás and Muñoz (1996) introduce a new non negative measure, which also must vanish, and can be computed by solving a dual pair of alternative but equivalent mathematical programming problems. Thus, one still achieves the advantages provided by Chen and Knez, since one globally focuses on the market and considers all the feasible arbitrage opportunities. Moreover, useful information about the state prices is obtained from the dual problem and, when the arbitrage does exist, the primal one provides a relationship between the measure and some associate arbitrage portfolios, and allows monetary interpretations for the measure. Finally, the new measure is continuous respect the initial data, and may be applied to test the efficiency of a single market, due to we can introduce it without considering more than one market.

Ideas of precedent paragraphs are useful to motivate and justify the present paper main objectives. We are interested in testing the financial markets efficiency and degree of integration. We will focus on the Spanish markets, and will apply methodologies derived from the previously mentioned measures. Hence, we will always consider all the arbitrage strategies available in the market(s), what is an important difference respect previous literature, and will compute the optimal one. Finally, we will always obtain the risk neutral probabilities, or a proxy for them when the arbitrage is possible.

Some cautions have been incorporated in order to guarantee that the agents can really implement the detected arbitrage portfolios. First, we work with perfectly synchronized high frequency data and two prices (bid-ask) for each asset, and consider that the investors can sell or buy any security, but the price is larger if they buy. Second, our hypotheses are very weak and compatible with any "reasonable" asset pricing model. In fact, our analysis will involve pure discount bonds and derivatives (future contracts and European put and call options) on the Spanish index IBEX-35, but we will only accept obvious assumptions about the prices at maturity or the expiration date. Third, we will estimate the transaction costs and discount them when arbitrage appears.

Although we only work with bonds and derivatives on the index, it is also interesting to analyze what happens if one incorporates the own index as well. This implies some technical problems, since the index is a more complex security, and we have preferred a first study to compare the index and the price of its usual replica composed by a future contract and a bond. We have computed the Chen and Knez, and the Balbás and Muñoz measures, and our main conclusion is that arbitrage is quite difficult after the transaction costs. However a surprising result is found, since both measures show similar evolution along the analyzed period. As we will show in the third section of the paper, this could suggest the existence of some relations between both measures, and more research about this question would be interesting.

The second study involves the already mentioned bonds and derivatives, and we have computed the Balbás and Muñoz measure. We have focused on two different periods. The first one, February-March 1997, is characterized by the stability in the financial markets, while the second, October 1997, is quite convulsive and characterized by large volatilities and the effect of the Asiatic crisis. 
Our main conclusions are again surprising. Even in the stable period we have that at many moments there are no positive state prices, positive discount factors, or risk-neutral probabilities. Hence, the theoretical classical results do not hold and, after discounting the transaction costs, the (cross-market) arbitrage is possible. Furthermore, the advantages of our methodology are clear, since the arbitrage portfolios are different from some moments to others, and the conclusion could not be proved if we had tested concrete strategies. If we look at the convulsive period, the arbitrage appears far more often, and the integration measure takes too large values. That means inefficiency along this days, result quite different to Kleidon and Whaley (1992). They studied the US markets during the crash of October 1987, and the different methodology could be perhaps an important key to explain the different conclusions.

The paper is organized as follows: Methodology is discussed in first section along with notation issues, basic assumptions, and some aspects of the integration measures that will be applied. Section 2 includes a detailed description of the markets and the data. Our empirical results are confined to the third section, and the fourth one is devoted to analyze how market makers work in practice and price the securities. Section 5 presents some specific arbitrage portfolios we have found, and last one concludes and summarizes the paper.

\section{I.- Methodology.}

We focus on a static pricing approach in the context of the classic model of Ingersoll (1987) with a finite number of states of nature. Hence, we will consider a two-period model characterized by two instants $t_{1}, t_{2}$ $\left(t_{1}<t_{2}\right.$.) and $n$ different assets. In order to incorporate the usual bid-ask spread, let $v_{k}$ and $c_{k}(k=1,2, \ldots, n)$ be two different prices at $t_{1}$, such that $0 \leq v_{k} \leq c_{k}$, where $v_{k}$ and $c_{k}$ are the bid and ask prices for the $\mathrm{k}^{\text {th }}$-asset, respectively. Whenever $v_{k}=0\left(c_{k}=\infty\right)$, it will be understood that the $\mathrm{k}^{\text {th }}$-asset can not be sold (bought). $E_{1}$, $E_{2}, \ldots, E_{m}$ denote the states of nature at $t_{2}$ with the subsequent matrix of payoffs $A=\left(a_{i k}\right)$ where $i=1,2, \ldots, m$ and $k=1,2, \ldots, n$; that is, $a_{i k}$ will be the payoff for the $\mathrm{k}^{\text {th }}$-asset in the state of nature $E_{i}$.

A portfolio in the feasible set is represented by a vector $x=\left(x_{1}, x_{2}, \ldots, x_{n}\right)$ such that $x_{k} \geq 0\left(x_{k} \leq 0\right)$ whenever $v_{k}=0\left(c_{k}=\infty\right)$. As usual, its price at $t_{1}$ is $P(x)=p_{1} x_{1}+p_{2} x_{2}+\ldots+p_{n} x_{n}$ where $p_{k}=v_{k}\left(p_{k}=c_{k}\right)$ if $x_{k} \leq 0$ $\left(x_{k} \geq 0\right)$ and its payoffs at $t_{2}$ are given by the vector $A x^{t}$ where $x^{t}$ represents the transpose of $x$.

For any feasible portfolio $\mathrm{x}$, let $\mathrm{x}^{+}$and $\mathrm{x}^{-}$be the portfolios given by the long and short positions respectively, i.e.

$$
\mathrm{x}^{+} \mathrm{k}_{\mathrm{H}}=\operatorname{Max}\left\{\mathrm{x}_{\mathrm{k}}, 0\right\} \text { and } \mathrm{x}_{\mathrm{k}}^{-}=\operatorname{Max}\left\{-\mathrm{x}_{\mathrm{k}}, 0\right\}
$$

for $\mathrm{k}=1,2, \ldots, \mathrm{n}$. The prices of $\mathrm{x}^{+}$and $-\mathrm{x}^{-}$will by denoted by $\mathrm{C}(\mathrm{x})$ and $\mathrm{V}(\mathrm{x})$, and clearly represent the prices of the purchased and sold assets, respectively.

Following the approach of Ingersoll (1987) or Prisman (1986), the feasible portfolio $\mathrm{x}$ is said to be an arbitrage strategy of the second type (from now on we will merely say "arbitrage strategy") if its price at $t_{1}$ is negative, 
and its price at $t_{2}$ is zero or greater than zero in all the states of nature. By readapting the proofs of Theorem 2, pp. 55 in Ingersoll (1987) and Theorem 12 in Balbás and Muñoz (1996), the following results may be easily established (see also Jouini and Kallal (1995)).

Theorem 1 There are no arbitrage strategies if and only if there exists at least a nonnegative vector of state prices, i.e. a nonnegative vector $\mathrm{d}=\left(\mathrm{d}_{1}, \mathrm{~d}_{2}, \ldots, \mathrm{d}_{\mathrm{m}}\right)$ such that for every $\mathrm{k}=1,2, \ldots, \mathrm{n}$

$$
\mathrm{v}_{\mathrm{k}} \leq \mathrm{a}_{1 \mathrm{k}} \mathrm{d}_{1}+\mathrm{a}_{2 \mathrm{k}} \mathrm{d}_{2}+\ldots+\mathrm{a}_{\mathrm{mk}} \mathrm{d}_{\mathrm{m}} \leq \mathrm{c}_{\mathrm{k}}
$$

Theorem 1 Assume that there are arbitrage (or cross-market arbitrage) strategies. For each feasible arbitrage strategy $x$, consider its current price $P(x)$, the price of the sold assets $V(x)$, and the price of the purchased assets $C(x)$. Then the quotients

$$
\mathrm{P}(\mathrm{x}) / \mathrm{V}(\mathrm{x}) \text { and }-\mathrm{P}(\mathrm{x}) /[-\mathrm{V}(\mathrm{x})+\mathrm{C}(\mathrm{x})]
$$

have a maximum value achieved at the same arbitrage portfolio $x^{*}$.

The integration measures $m$ and $l$ will be given by

$$
\mathbf{m}=\mathrm{P}\left(\mathrm{x}^{*}\right) / \mathrm{V}\left(\mathrm{x}^{*}\right) \text { and } \mathbf{l}=-\mathrm{P}\left(\mathrm{x}^{*}\right) /\left[-\mathrm{V}\left(\mathrm{x}^{*}\right)+\mathrm{C}\left(\mathrm{x}^{*}\right)\right]
$$

or zero if no arbitrage opportunities do exist. The relationship $\mathbf{l}=\mathbf{m} /(2-\mathbf{m})$ may be easily proved (Balbás and Muñoz (1996)), and the inequalities

$$
0 \leq \mathbf{l} \leq \mathbf{m} \leq 1
$$

are obvious. $\mathbf{m}$ and $\mathbf{l}$ give information in monetary terms, what allows to analyze markets with friction since one can discount the transactions costs after computing the (relative) arbitrage profits given by $\mathbf{m}$ and $\mathbf{l}$. Furthermore, since $\mathbf{m}$ and $\mathbf{I}$ represent monetary arbitrage profits, it is clear that the integration level decreases when these measures increase and conversely. We will compute very small values of the measures when the markets are well integrated.

The integration measure of Chen and Knez (1995) is introduced by means of the state prices. In fact, let us consider that the first $s$ assets can be bought or sold in a first market $\mathbf{M}_{1}$, and the assets number $s+1, s+2, \ldots, n$ correspond to a second market $\mathbf{M}_{2}$. Assume that no arbitrage strategies can be found in the market $\mathbf{M}_{\mathbf{z}}$ $(z=1,2)$. Then, we can find the set $D_{z} \subset R^{m}$ of nonnegative state prices for $M_{\mathbf{z}}(z=1,2)$ and the measure of Chen and Knez is given by the infimum value of the set

$$
\left\{\left\|d-d^{\prime}\right\|^{2}: d \in \mathbf{D}_{1} \text { and } d^{\prime} \in \mathbf{D}_{2}\right\}
$$

where $\|$. $\|$ represents the usual Euclidean norm. Denoting this measure by a (or $\mathbf{a}\left(\mathbf{M}_{1}, \mathbf{M}_{2}\right)$ if necessary), it trivially follows from theorem 1.1 that $\mathbf{a}=0$ if there are no cross-market arbitrage strategies, and the converse may be demonstrated by readapting the proof of Chen and Knez (1995). Therefore, the markets are perfectly integrated if and only if $\mathbf{a}=0$. When the measure a does not vanish but is small enough, the state prices of both markets are "near", and the markets are also "near" of perfect integration. If a takes high values then the 
markets price the securities by applying quite different criteria (the state prices are "far") and the integration level is too low.

As shown in Balbás and Muñoz (1996), the measures $\mathbf{m}$ (or $\mathbf{l}$ ) and a are quite different, and give different information about the integration level, although some relations between them can be found. It is important to point out that some simple examples may be given such that both measures take very different values, and therefore, the distance of the state prices (a) and the relative arbitrage profits (m) are far from being equivalent criteria. The reason is clear: $m$ computes the markets discrepancy when pricing the real assets or portfolios and a computes discrepancy in the state prices or discount factors. Of course, the discount factors are specific criteria to price the real securities, but quite different discount factors can sometimes lead to similar prices for these real securities. Thus, $m$ will be small if $a$ is small too, but for incomplete markets, there are situations such that $\mathbf{m}$ almost vanishes and a remains large (see Balbás and Muñoz (1996)).

As mentioned above, we concentrate on the Spanish Financial Markets and in particular we examine options on futures, futures on a stock index, the stock index and the riskless pure discount bond. Two different situations will be studied. First, we compute the Chen and Knez and the Balbás and Muñoz measures by comparing the current prices of the index and its usual replica with the riskless asset and the future contract. The states of nature are given by a set of 1,200 equidistant values in the interval $\left(I_{1}-600, I_{1}+600\right)$, where $I_{1}$ is the value of the stock index at $t_{1}$.

Our second study involves all assets and it is undoubtedly the most important one. In this case we have only tested the Balbás and Muñoz measure, since it gives information in monetary terms, and may be easily computed when working with a large number of assets and data. Moreover, following the approach of Balbás et al, this measure could also be determined if one applied dynamic assumptions to pricing assets. The states of nature will be simplified and basically given by the options striking prices. They will be finite and given by $I_{2}$, the index value at $t_{2}$, which will be discrete. It will be assumed that $I_{2}$ will move between the 60 per cent and up to the 140 per cent of $I_{1}$, where $I_{1}$ is either the index present value or the average price of the future contract. $^{1}$

It may be easily proved that no new arbitrage portfolios appear after the simplification, and therefore, an empirical analysis implemented from more complicated (and, of course, more restrictive) asset pricing models would lead to lower degree of efficiency and integration.

As usual, the call (put) options final payoff (at $t_{2}$ ) has been assumed to be determined by $\operatorname{Max}\left\{I_{2}-E, 0\right\}$ (Max $\left.\left\{E-I_{2}, 0\right\}\right)$ where $E$ represents the striking price. The shadow asset ${ }^{2}$ final payoff will equal $I_{2}$, and the bond final payoff will always be 1 , and does not depend on $I_{2}$. Therefore, if one considers that $E_{1}, E_{2}, \ldots, E_{S}$ are

\footnotetext{
${ }^{1}$ In our particular empirical analysis, this is a very realistic assumption since $t_{2}-t_{1}$ is never longer than one month.

${ }^{2}$ The shadow asset is the usual replica of the stock index: the future contract and the pure discount bond.
} 
the striking prices for the different options available in the market at a given moment, and we again assume that $0.6 \mathrm{I}_{1} \leq \mathrm{I}_{2} \leq 1.4 \mathrm{I}_{1}$, it follows that the final payoff of any feasible portfolio $\mathrm{x}$ is given by a function of $\mathrm{I}_{2}$ evaluated at a given value in the interval $\left(0.6 \mathrm{I}_{1}, 1.4 \mathrm{I}_{1}\right)$. Furthermore, the following result trivially holds

Lemma 1 The feasible portfolio $x$ has nonnegative final payoff for any value of $I_{2}$ if and only if $x$ has nonnegative final payoff for $\mathrm{I}_{2}=0.6 \mathrm{I}_{1}, \mathrm{E}_{1}, \mathrm{E}_{2}, \ldots, \mathrm{E}_{\mathrm{S}}$, or $1.4 \mathrm{I}_{1}$.

The above lemma guarantees that we can work with a finite number of states of nature and hence, apply the results shown in this section. Of course, the states of nature may change (the available options or the value $\mathrm{I}_{1}$ may change) if $t_{1}$ changes. Hence, our process has two stages. We first check for the absence of arbitrage opportunities by applying Theorem 1 and, whenever riskless profits are feasible, we obtain, in a second stage, the optimum arbitrage portfolio whose existence is guaranteed by Theorem 2 .

\section{2.- Markets and data.}

The Spanish Financial Markets considered in our study are the Sistema de Interconexión Bursátil Español (SIBE), the Mercado Español de Futuros Financieros sobre Renta Variable (MEFF-RV) and the Mercado de Deuda Anotada (MDA). MEFF-RV is one of the most important futures and options exchange in Europe and is ranked among the first in the world. Specifically, the IBEX-35 stock index future was the most traded contract in the world during 1994 and 1995 (Sutcliffe (1997), pp.59).

The IBEX-35 index is a capitalization-weighted index comprising the 35 most liquid Spanish stocks traded in the Continuous Market (SIBE) and this index is the underlying asset for IBEX-35 Plus future contracts. The IBEX-35 Plus European options are based on the future contract. All derivatives are only available in MEFF$\mathrm{RV}$. The premium quotation is measured in index points and each point is equivalent to 1,000 pesetas and the maturity date is the third Friday of the expiration month. It should be emphasized that all derivatives considered take as settlement price at expiration the arithmetic average index value between 16:15 and 16:45 hours on the expiration date, taking a value per minute. Finally, for all the minutes of the same day, the daily interest rate corresponding to the pure discount bond - traded in MDA - whose maturity is closest to the maturity of the derivative contracts is used as a proxy for both the lending and borrowing rate of interest.

The trading hours at the SIBE are from 10:00 a.m. to 5:00 p.m., while the MEFF-RV is opened from 10:00 a.m. to 5:15 p.m. In this study, minute by minute bid and ask prices for all securities are employed during two intervals: a stable one - from February 24 to March 21, 1997- and a very convulsive period - from October 22 to 30,1997 -, and at any minute we have applied a two-periods model, being $t_{1}$ the corresponding minute and $t_{2}$ the expiration date. All derivatives have the same expiration date, being March 21, 1997 for the first analysis and November 21, 1997 for the second one. 
There are two criticisms which usually appear when empirical papers show the existence of arbitrage opportunities. First, the data must be perfectly synchronized, and second, the transaction costs must be discounted. It is important to point out that we work with high frequency data and two prices (bid-ask) for each asset, so the arbitrage strategies are detected under a very hard assumption: an investor can sell or buy any portfolio, but the price is larger when he/she buys it. Furthermore, the handling of the bid and ask prices of the securities, instead of the last transaction price, eliminates both the non-synchronous bias and the non-trading effect, and in this way, the highest possible precision is accomplished. In order to avoid the difficulties implied by the stock market transaction costs, whenever the index is needed to design an arbitrage strategy, it will be replaced by its usual replica. Hence, we will really work with the options, the riskless pure discount bond with maturity at the expiration date, and a shadow asset composed by the future contract and the bond. If $F$ ( $F^{\prime}$, with $F^{\prime} \geq F$ ) is the bid (ask) index future price, then $F /(1+r)\left(F^{\prime} /(1+r)\right)$ will be the bid (ask) price for the shadow asset, being $r$ the interest rate from $t_{1}$ to $t_{2}$, which is obtained from MDA.

\section{III.- Empirical Results.}

As mentioned above we begin by examining a stable period that corresponds to 19 consecutive trading days prior to March-97 expiration date where the computation of the payoff matrix for each minute has been obtained basing on the IBEX-35 stock index. This yields 420 trading minutes per day and 7,980 for the whole period.

The level of integration between the IBEX-35 Plus futures contract and its underlying asset has been observed. Although our particular extension of the Chen and Knez (1995) measure does take into account the bid and ask future contract prices, in order to compare $a$ and $\mathbf{m}$ we make use of Chen and Knez original implementation, so the average price is employed in our calculations. Results are given in Figure 1 where we plot these measures versus their corresponding minute for March 4, 97 - we consider this date as representative of the market general behavior during this stable interval.

Despite $\mathbf{a}$ is based on state prices and $\mathbf{m}$ uses relative profits from an optimum arbitrage portfolio, both measures follow an identical pattern. This shocking finding may deserve future research as a relationship between both measures in a restricted context like this might exist. The effect of transaction costs can be discounted by simply subtracting 32.58 basic points to the value of $\mathbf{m}^{3}$ Hence, by examining our results for $\mathbf{m}$, it may be concluded that these two markets are perfectly integrated.

\footnotetext{
${ }^{3}$ Using 1 as an integration measure allows to discount transaction costs $(T C)$. If $T C$ is proportional to the total traded value $(-V(x)+C(x))$, which may well be assumed in this particular case, it follows that $\mathbf{m}$ must be less than the ratio $2 T C /(1+T C)$ for these markets to be integrated. This ratio amounts to 32.58 basic points in our context.
} 


\section{Figure 1}

Chen and Knez (a) and Balbas and Muñoz (m) measures for the level of integration between the IBEX-35 Plus futures contract and its underlying asset versus time for March 4, 1997.

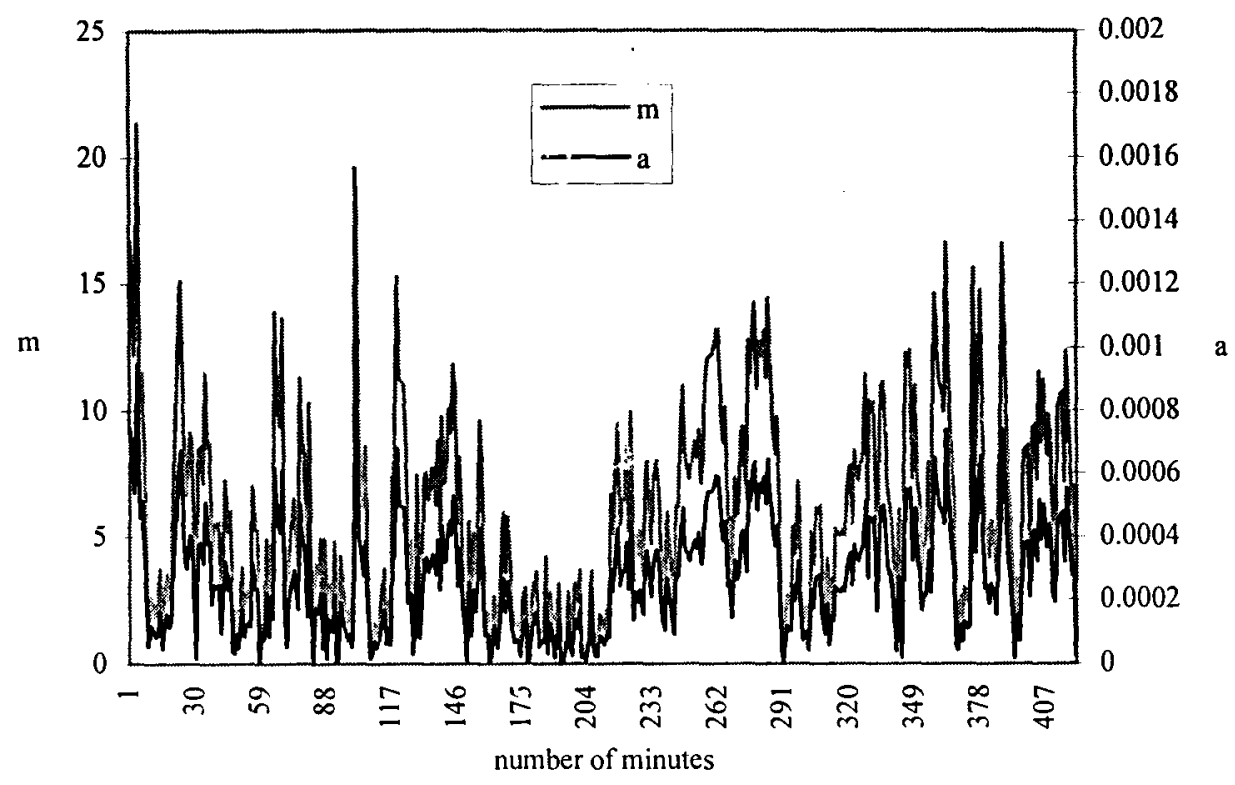

For the same period, we have studied efficiency and integration for the IBEX-35 index (replaced by its usual replica when needed), its future contracts, pure discount bonds and the European call and put options on the future. Note that the Chen and Knez measure can not be employed under the very general conditions used in our design. In particular, a it can not be computed if there are arbitrage opportunities within each market considered (see Chen and Knez (1995), assumption 2, po. 295). Moreover, as Kempf and Korn (1996) point out, it is impossible to judge the significance of any difference found between two estimated values of $\mathbf{a}$.

Table 1 reports the number of minutes in which arbitrage opportunities where detected along with the maximum value of $\mathrm{m}$ for each day. The average number of available assets is 26 (see column 2). Except for the first week, results show that most of the days riskless profits can be earned, even after considering transaction costs (see columns 3 and 4). Arbitrage strategies are possible during a 1.2 per cent of the minutes observed and this figure decreases by 0.46 per cent when taking into account transaction costs. ${ }^{4}$ The extremely large values obtained for March 14 and 21 may well be attributed to a serious misspricing caused by a mistake in the premiums offered and demanded (the corresponding arbitrage opponiunities only last for one minute). Furthermore, these are the unique strategies that exclusively involve the options market.

\footnotetext{
${ }^{4}$ Transaction costs in the Spanish options and futures markets amount to 500 pesetas per contract, if we assume an average index value of 5,400 index points, this implies that $\mathrm{m}$ must be greater than 1.8 basic points in order to make up for transaction costs.
} 
Table 1

The first column gives the corresponding day. The second one indicates the maximum number of assets considered. Third column gives the number of minutes in which arbitrage opportunities are detected under the assumption of absence of transaction costs (TC), while fourth column takes them into account. Fifth column shows the maximum value of $\mathbf{m}$ in basic points and annualized intraday volatility is given in column 6. All derivatives have as expiration date March 21 , 1997.

\begin{tabular}{cccccc} 
day & assets & without TC & with TC & maximum m & volatility \\
\hline 240297 & 27 & 0 & 0 & 0.00 & $11.60 \%$ \\
250297 & 24 & 0 & 0 & 0.00 & $17.66 \%$ \\
260297 & 28 & 1 & 0 & 1.52 & $12.79 \%$ \\
270297 & 25 & 0 & 0 & 0.00 & $10.30 \%$ \\
280297 & 25 & 1 & 1 & 29.63 & $15.69 \%$ \\
40397 & 26 & 0 & 0 & 0.00 & $9.80 \%$ \\
50397 & 26 & 10 & 10 & 45.01 & $14.28 \%$ \\
60397 & 31 & 2 & 1 & 3.53 & $11.17 \%$ \\
70397 & 24 & 4 & 3 & 64.05 & $12.24 \%$ \\
100397 & 24 & 10 & 5 & 15.78 & $11.56 \%$ \\
110397 & 32 & 26 & 8 & 8.33 & $11.97 \%$ \\
120397 & 29 & 5 & 4 & 17.58 & $10.75 \%$ \\
130397 & 28 & 2 & 1 & 3.45 & $14.38 \%$ \\
140397 & 31 & 6 & 6 & 4704.30 & $15.02 \%$ \\
170397 & 27 & 6 & 4 & 5.40 & $12.78 \%$ \\
180397 & 21 & 12 & 6 & 7.34 & $12.15 \%$ \\
190397 & 24 & 1 & 1 & 42.27 & $10.78 \%$ \\
200397 & 25 & 6 & 5 & 12.92 & $11.64 \%$ \\
210397 & 15 & 4 & 4 & 3025.18 & $12.68 \%$ \\
\hline Total/Mean & 26 & 96 & 59 & - & $12.59 \%$
\end{tabular}

The number of arbitrage opportunities is grouped into 30 minute intervals in Table 2 and its intraday pattern is illustrated in Figure 2. This pattern follows a U-shape from noon on and it achieves its minimum in the interval that goes from 13:30 to 14:30 in which no arbitrage opportunities are detected after considering transaction costs. ${ }^{5}$ More than half of them $(51.05 \%$ and $55.92 \%$ without and with transaction costs, respectively) take place in the last two hours of the trading session.

\footnotetext{
SIs it because of lunch time?. No free lunch at lunch time?
} 
Table 2

The first column gives the moments, in which arbitrage opportunities are detected, clustered in 30 minutes intervals. The second one indicates the number of minutes under the assumption of absence of transaction costs (TC), while the third column takes them into account. Fourth and fifth column show the percentage of arbitrage opportunities. All derivatives have as expiration date March 21, 1997.

\begin{tabular}{ccccc} 
& \multicolumn{2}{c}{ Number of minutes } & \multicolumn{2}{c}{ Percentage } \\
\cline { 2 - 5 } Interval & without TC & with TC & without TC & with TC \\
\hline $1001-1030$ & 1 & 1 & $1.04 \%$ & $1.69 \%$ \\
$1031-1100$ & 5 & 2 & $5.21 \%$ & $3.39 \%$ \\
$1101-1130$ & 6 & 5 & $6.25 \%$ & $8.47 \%$ \\
$1131-1200$ & 1 & 1 & $1.04 \%$ & $1.69 \%$ \\
$1201-1230$ & 15 & 3 & $15.63 \%$ & $5.08 \%$ \\
$1231-1300$ & 9 & 6 & $9.38 \%$ & $10.17 \%$ \\
$1301-1330$ & 4 & 4 & $4.17 \%$ & $6.78 \%$ \\
$1331-1400$ & 1 & 0 & $1.04 \%$ & $0.00 \%$ \\
$1401-1430$ & 1 & 0 & $1.04 \%$ & $0.00 \%$ \\
$1431-1500$ & 4 & 4 & $4.17 \%$ & $6.78 \%$ \\
$1501-1530$ & 7 & 3 & $7.29 \%$ & $5.08 \%$ \\
$1531-1600$ & 9 & 5 & $9.38 \%$ & $8.47 \%$ \\
$1601-1630$ & 17 & 15 & $17.71 \%$ & $25.42 \%$ \\
$1631-1700$ & 16 & 10 & $16.67 \%$ & $16.95 \%$ \\
\hline Total & 96 & 59 & &
\end{tabular}

Figure 2

Number of arbitrage opportunities grouped into 30 minute intervals.

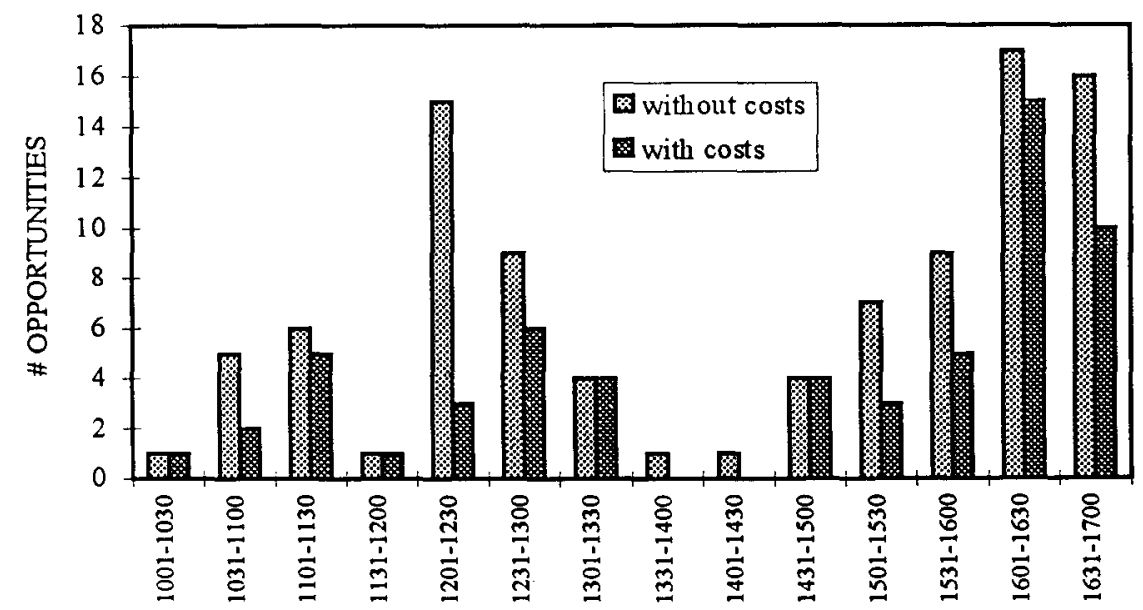

A call for caution is an order here before jumping into conclusions about efficiency in Spanish markets. Optimum arbitrage strategies are derived whenever state prices do not exist in order to compute the value of $\mathbf{m}$. Therefore, arbitrage opportunities that are the consequence of an efficiency failure (those that only require 
operations in one market) might also exist. This argument led us to compute the values of $\mathbf{m}$ after dropping the stock index and the pure discount bond in order to check for efficiency in the options market. Only two arbitrage opportunities were detected in this case and they coincide with the ones found for March 14 and 21 giving thus the same values of $\mathbf{m}$. Consequently, we can establish that option markets have a high degree of efficiency, being desintegration the key factor in explaining these deviations during this stable period. Nonetheless, the possibility of arbitrage exists.

In order to analyze efficiency and integration in high volatility periods, next we study the effect of October 1997 Asiatic crisis in the Spanish markets. During this convulsive period, serious declines were experienced, leading to extremely large intraday volatilities from October 27 to October 29,1997 (it averaged $48,34 \%$ in annual terms). Unprecedented trading volumes were reached in the options market (October 27) and in the stock and futures markets (October 28). Also, the Spanish stock market index bore both its tenth greatest fall (October 27) and its largest increase (October 29) in the last six years (4,40\% and 5,66\%, respectively).

Due to the abnormal number of limit orders waiting to be traded, the opening of SIBE was delayed and the IBEX-35 stock index was not occasionally available for the days above. This fact forces us to take the IBEX-35 Plus futures contract average price as $I_{1}$ (the basis to build the payoffs matrix).

For this period, our main results are given in Table 3. The average number of available assets (50) is twice as much as the one for normal trading conditions. Note that the number of minutes in which state prices do not exist is much higher for October 27, 28 and 29 (it accounts for $9.15 \%$ out of the overall trading minutes of these days) and also larger values of $m$ are encountered for the whole period - especially on the 27 th and the 28 th -. It should be emplasized that 20 out of a total of 143 arbitrage opportunities exclusively concern the options market. No additional arbitrage strategies are possible when dropping the future contract and the pure discount bond. Hence, although desintegration accounts for a larger number of deviations, inefficiency in options market plays an important role in this unstable period. In any event, our results are different to Kleidon and Whaley (1992). They studied the degree of integration among US markets for stocks, futures and options prior to and during the October 1987 market crash and reported that the usual links between futures and option markets were largely intact. 


\section{Table 3}

The first column gives the corresponding day. The second one indicates the maximum number of assets considered. Third column gives the number of minutes in which arbitrage opportunities are detected under the assumption of absence of transaction costs (TC), while fourth column takes them into account. Fifth column shows the maximum value of $\mathbf{m}$ in basic points and annualized intraday volatility is given in column 6. All derivatives have as expiration date November 21 , 1997.

\begin{tabular}{cccccc} 
day & assets & without TC & with TC & maximum m & volatility \\
\hline 221097 & 40 & 2 & 2 & 7.21 & $16.02 \%$ \\
231097 & 45 & 6 & 4 & 476.19 & $22.47 \%$ \\
241097 & 44 & 4 & 2 & 626.78 & $15.40 \%$ \\
271097 & 47 & 11 & 6 & 1785.71 & $27.84 \%$ \\
281097 & 55 & 21 & 18 & 4199.82 & $79.43 \%$ \\
291097 & 59 & 94 & 79 & 357.14 & $37.75 \%$ \\
301097 & 63 & 5 & 4 & 208.33 & $38.17 \%$ \\
\hline Total/Mean & 50 & 143 & 115 & & $33.87 \%$ \\
\hline
\end{tabular}

In order to establish the accuracy of our conclusions, it is important to stress again the generality of our design. All assets quoted in these markets along with perfectly synchronized best bid and ask prices are considered Furthermore, transaction costs are discounted and all possible arbitrage strategies are taken into account when detecting misspricing in the markets. ${ }^{6}$ Hence, our results clearly validate the existence of possible riskless profits during stable periods as the one analyzed and that this possibility increases when facing high volatility situations.

\section{IV.- On the Bid-Ask Spread}

The existence of arbitrage has been tested under hard assumptions that can be relaxed in many practical situations.. First, we have only considered static models, and dynamic arbitrage portfolios have never been analyzed. Second, the prices are greater if the investors buy the assets $\left(c_{k} \geq v_{k}\right)$. Third, the ratio $I_{2} / I_{1}$ has been always assumed to be between 0.6 and 1.4 , too large spread if $t_{2}-t_{1}$ is small enough. So for instance, two or three days before the expiration date (before $t_{2}$ ) we could have taken $0.2 \leq I_{2} / I_{1} \leq 1.2$, and some hours before $t_{2}$ this interval could have been far smaller.

These assumptions have clear advantages because we can be absolutely sure about the fundamental conclusion, i. e. , cross-market arbitrage portfolios will appear. But it may be important to compute the integration measures after relaxing our hypotheses, and the present section is devoted to partially develop this idea.

We will specifically concentrate on the stable period, and the bid-ask spread. This spread is large and has an important effect in our analysis due to we have never worked with the price of real transactions.

\footnotetext{
${ }^{6}$ Lee and Nayar (1993) and Sternberg (1994) study the level of integration between Standard and Poor's 500 futures and options markets but they only tested for the existence of put-call parity violations with transaction data.
} 
The bid-ask spread has been removed only for the most traded option. Of course, this option (which is different from some days to others) often presents the biggest and closest to one bid/ask ratio, and therefore, if we had considered another security, the measure $m$ would have been larger. Anyway, the measure clearly increases, and the basic results are shown in the following tables.

\section{Table 4}

The bid-ask spread has been removed for the most traded option and the bid price is used in both buy and sell operations for this particular asset. The first column gives the corresponding day. The second one gives the number of minutes in which arbitrage opportunities are detected under the assumption of absence of transaction costs (TC), while third column takes them into account. Fourth column shows the maximum value of $m$ in basic points. All derivatives have as expiration date March 21, 1997.

\begin{tabular}{cccc} 
date & without costs & with costs & maximum m \\
\hline 240297 & 37 & 37 & 275 \\
250297 & 3 & 3 & 303 \\
260297 & 2 & 1 & 18 \\
270297 & 26 & 11 & 6 \\
280297 & 1 & 1 & 32 \\
40397 & 29 & 12 & 463 \\
50397 & 76 & 76 & 719 \\
60397 & 2 & 1 & 4 \\
70397 & 5 & 4 & 64 \\
100397 & 10 & 5 & 16 \\
110397 & 97 & 66 & 1860 \\
120397 & 10 & 5 & 18 \\
130397 & 140 & 114 & 1750 \\
140397 & 62 & 49 & 4803 \\
170397 & 10 & 8 & 5 \\
180397 & 12 & 6 & 7 \\
190397 & 6 & 6 & 249 \\
200397 & 7 & 7 & 28 \\
210397 & 10 & 10 & 4420 \\
\hline Total & 545 & 422 &
\end{tabular}


Table 5

The bid-ask spread has been removed for the most traded option and the ask price is used in both buy and sell operations for this particular asset. The first column gives the corresponding day. The second one gives the number of minutes in which arbitrage opportunities are detected under the assumption of absence of transaction costs (TC), while third column takes them into account. Fourth column shows the maximum value of $\mathbf{m}$ in basic points. All derivatives have as expiration date March 21, 1997.

\begin{tabular}{cccc} 
date & without costs & with costs & maximum m \\
\hline 240297 & 0 & 0 & 0 \\
250297 & 0 & 0 & 0 \\
260297 & 24 & 23 & 238 \\
270297 & 92 & 75 & 2591 \\
280297 & 22 & 22 & 234 \\
40397 & 78 & 40 & 183 \\
50397 & 109 & 101 & 515 \\
60397 & 72 & 71 & 500 \\
70397 & 14 & 13 & 1042 \\
100397 & 10 & 5 & 16 \\
110397 & 152 & 125 & 210 \\
120397 & 44 & 22 & 18 \\
130397 & 402 & 401 & 6756 \\
140397 & 76 & 61 & 4704 \\
170397 & 139 & 118 & 1053 \\
180397 & 36 & 30 & 1000 \\
190397 & 241 & 241 & 5417 \\
200397 & 11 & 11 & 2105 \\
210397 & 33 & 33 & 3025 \\
\hline Total & 1555 & 1392 &
\end{tabular}

The differences between tables 4 or 5 and table 1 are obvious, what proves that the market makers prices often lead to arbitrage. Furthermore, the measure and the arbitrage profits are quite large at many instants (specially when the ask price is used for both, buy and sell) what should be used by the investors to offer new prices. Hedging (with arbitrage portfolios) would be feasible if new agents accepted these prices

Once again we have obtained a surprising fact The bid-ask spread is high, and that suggests some new strategies to invest. At many moments the agents could analyze the bid-ask spread for many securities, and offer new prices without assuming any kind of risk. This should lead to smaller spreads, and market makers would be more constrained when they price the assets. But that is not what the empirical results reveal.

\section{V.- Arbitrage Strategies.}

Next we examine an example of an optimum arbitrage strategy that could have been implemented in the October 1997 stock market crash. We also check for possible improvements from the market maker's point of view by removing the bid-ask spread for the most traded option. 
Our example refers to an arbitrage opportunity for October 29, 1997. In this trading session 59 different assets were traded in all markets considered and 40 were being quoted at 17:05. Table 6 gives best bid and ask prices for all available assets at this moment. There were no state prices in this case so arbitrage was feasible. $\mathbf{m}$ takes a value of 56 basic points and its corresponding optimum arbitrage strategy gives the following transaction set: long position in 200 units of the bond, buying a call option with a strike price of 6500 and two put options with a strike price of 6300 , selling a call option with a strike price of 6300 and two put options with a strike price of 6400 , all units measured in index points. Note that although some abnormalities may be observed in the put option prices, the optimum strategy is not trivial. Figure 3 plots the resulting total payoff of this portfolio at $\mathrm{t}_{2}$ (November 21, 1997). It follows that if the stock index value at the expiration date lies between 6300 and 6500 , additional profits are possible, so we are facing an arbitrage opportunity of the second type (see Ingersoll (1987, pp. 153)).

\section{Table 6}

Best bid and ask prices for all quoted assets in October 29, 1997 at 17:05. Bold type is used for those assets involved in the optimum arbitrage portfolio and in parenthesis sold or bought units are given. All derivatives have as expiration date November 21, 1997.

Call Options

Put Options

\begin{tabular}{|c|c|c|c|c|c|}
\hline Strike price & Bid price & Ask price & Strike price & Bid price & Ask price \\
\hline 5700 & 400 & N.A. & 5500 & 65 & N.A. \\
\hline 5800 & N.A. & 800 & 5600 & 50 & N.A. \\
\hline 6300 & $355(1)$ & 375 & 5700 & 85 & N.A. \\
\hline 6350 & 325 & 345 & 5800 & N.A. & 160 \\
\hline 6400 & 295 & 315 & 6100 & 190 & 210 \\
\hline 6450 & 270 & 290 & 6150 & 200 & 220 \\
\hline 6500 & 240 & $250(1)$ & 6200 & 220 & 240 \\
\hline 6550 & 220 & 240 & 6250 & 235 & 255 \\
\hline 6600 & 190 & 210 & 6300 & 255 & $275(2)$ \\
\hline 6700 & N.A. & 198 & 6400 & $325(2)$ & 350 \\
\hline 6800 & 51 & N.A. & 6450 & N.A. & 450 \\
\hline 6850 & 15 & 120 & 6500 & N.A. & 400 \\
\hline 6900 & 40 & 105 & 6600 & 350 & 430 \\
\hline 6950 & 10 & N.A. & 6700 & N.A. & 650 \\
\hline 7000 & 33 & 83 & 7300 & 603 & N.A. \\
\hline 7050 & 18 & N.A. & 7500 & 800 & N.A. \\
\hline 7100 & 25 & 50 & & & \\
\hline 7200 & N.A. & 40 & Asset & Bid price & Ask price \\
\hline 7250 & 10 & 45 & IBEX-35 & 6375.86 & 6378.85 \\
\hline 7350 & N.A. & 40 & Bond & 0.997 & $0.997(200)$ \\
\hline 7400 & N.A. & 50 & & & \\
\hline 7500 & 5 & N.A. & & & \\
\hline
\end{tabular}




\section{Figure 3}

Final payoffs for the optimum arbitrage strategy in October 29, 1997 at 17:05.

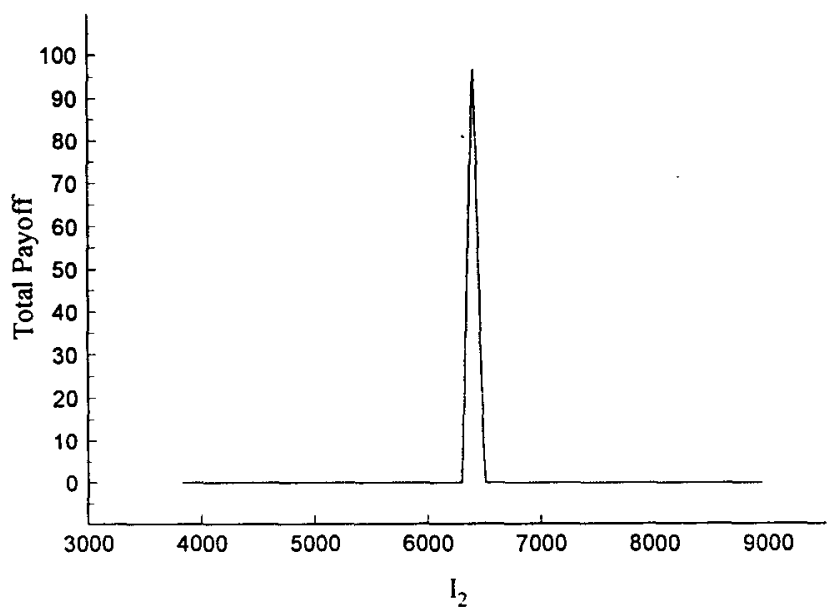

Now, if we remove the bid-ask spread for the most traded option (the put option with a strike price of 6400) and we set them both equal to the best ask price, profit through arbitrage increases. In this case, the optimum strategy is given by the following transactions: buying for 275 index points two put options and for 430 one put option with strike prices 6300 and 6600 , respectively and selling for 350 three put options with a strike price of 6400 . This combined positions lead to a profit of 70 index points (m equals 667 basic points). Again, an arbitrage opportunity of the second type follows and its total payoffs at $t_{2}$ are illustrated in Figure 4 .

Figure 4

Final payoffs for the optimum arbitrage strategy in October 29, 1997 at 17:05 when we remove the bid-ask spread for the most traded option (the put option with a strike price of 6400 ) and we set them both equal to the best ask price.

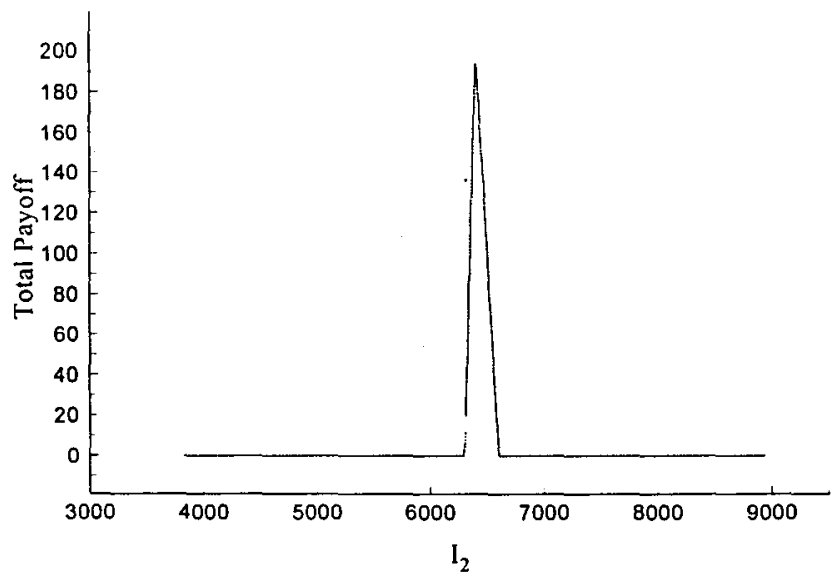




\section{VI.- Conclusions}

All along the paper we have empirically tested the integration level among different Spanish financial markets and have computed some of the integration measures recently appeared in the literature. These measures are derived from the basic assumptions to price assets, like the Law of One Price, or the absence of cross-market arbitrage opportunities, but provide a new methodology respect previous empirical papers, since one globally tests the markets, and not only some specific or concrete well known arbitrage strategies.

We have worked with the highest possible precision and under the weakest hypotheses. So, perfectly synchronized high frequency data are used, and the bid-ask spread or the transaction costs are always incorporated. On the other hand, we only accept obvious assumptions about the prices of some derivative securities at the expiration date.

The results are surprising for several reasons. First, when we work with the index IBEX-35 and its usual replica, different integration measures show similar path, what means that different criteria lead to similar conclusions about the integration level. Second, and more important, the (cross-market) arbitrage portfolios appear in practice, what suggests some disintegration among the tested markets. This fact is more clear along some days in October 1997, a convulsive period characterized by the effects of the Asiatic crisis.

It has also been partially analyzed how the market makers price the different securities. It has been shown that, at many moments, they can hedge many positions with an arbitrage portfolio, and the arbitrage profits are specially large for them.

Finally, the methodology also provides the risk neutral probability measures, or a proxy for them when the absence of arbitrage fails.

\section{References}

Back, K. and S.R. Pliska, 1991, "On the Fundamental Theorem of Asset Pricing with an Infinite State Space", Journal of Mathematical Economics, 20, 1-18.

Balbás, A. and M.J. Muñoz, 1996, "Measuring the Degree of Fulfillment of the Law of One Price. Applications to Financial Markets Integration", Universidad Carlos III de Madrid, Working Paper 9675 Economic Series 31.

Balbás, A. , P.J. Guerra, and M.J. Muñoz, "Measuring the Arbitrage Opportunities in an Intertemporal Dynamic Asset Pricing Model", Lectures Notes in Economics and Mathematical Systems, SpringerVerlag (to appear). 
Brenner, R.J. and K.F. Kroner, 1995, "Arbitrage, Cointegration, and Testing the Unbiasedness Hypothesis in Financial Markets". Journal of Financial and Quantitative Analysis, Vol. 30, No 1, $23-42$.

Chen, Z. and P.J. Knez, 1995, "Measurement of Market Integration and Arbitrage", The Review of Financial Studies Vol. 8, No 2, 563-79.

Hansen, L.P. and S.F. Richard, 1987, "The Role of Conditioning Information in Deducing Testable Restrictions Implied by Dynamic Asset Pricing Models". Econometrica, Vol. 55, No 3, 587-613.

Hansen, L.P. , J. Heaton and E.G.J. Luttner, 1995, "Econometric Evaluation of Asset Pricing Models". The Review of Financial Studies, Vol. 8, No 2, 237-74.

Harris, F.H. , T.H. McInish, G.L. Shoesmith and R.A. Wood, 1995, "Cointegration, Error Correction, and Price Discovery on Informatically Linked Security Markets", Journal of Financial and Quantitative Analysis, Vol. 30, No 4, 563-79.

Harrison, J. and D. Kreps, 1979, "Martingales and Arbitrage in Multiperiod Security Markets": Journal of Economic Theory, Vol. 20, 381-408

Hudson, R., M. Dempsey, and K. Keasey, 1996, "A Note on the Weak Efficiency of Capital Markets: The Application of Simple Teclnical Trading Rules to U.K. Stock Prices 1935 to 1994". Journal of Banking and Finance, 20, 1121-32.

Ingersoll, J.E, 1987, "Theory of Financial Decision Making". Rowman \& Littlefield Publishers Inc.

Jouini, E. and H. Kallal, 1995, "Martingales and Arbitrage in Securities Markets with Transaction Costs". Journal of Economic Theory, 66, 178-197.

Kamara, A. and T.W. Miller, 1995, "Daily and Intradaily Tests of European Put-Call Parity". Journal of Financial and Quantitative Analysis Vol. 30, No 4, 519-41.

Kempf, A. and O. Korn, 1996, "Trading System and Market Integration". Proceedings of the $6^{\text {th }}$ AFIRColloquium. Nuremberg. October 1-3, 1709-28.

Kleidon, Allan W. and R.E. Whaley, 1992, " One market? stocks, futures and options during October 1987", The Journal of Finance, Vol. XLVII, No 3, 851-877.

Lee, J.H. and N. Nayar, 1993, "A Transactions Data Analysis of Arbitrage between Index Options and Index Futures". Journal of Futures Markets, 13, No 8, 889-902.

Prisman E.J., 1986 "Valuation of Risky Assets in Arbitrage Free Economies with Frictions". The Journal of Finance, Vol. 41, No 3, 545-56.

Protopapadakis A. and H.R. Stoll, 1983, "Spot and Futures Prices and the Law of One Price". The Journal of Finance, Vol. 38, No 5, 1431-55.

Sternberg, Joel S. ,1994, "A reexamination of put-call parity on index futures". Journal of Futures Markets, 14, No 1, 79-101.

Sutcliffe,Charles, 1997, Stock Index Futures: Theories and International Evidence, International Thomson Business. 